\title{
Reaction time to different wavelengths at various luminances ${ }^{1}$
}

\author{
JOAN DIEHL POLLACK \\ COLUMBIA UNIVERSITY $Y^{2}$
}

The present investigation is concerned with determining whether or not differences in the reaction times exist in a human subject's responses to 6 different wavelengths equated at 5 levels of luminance. The heterochromatic matching was done by the method of flicker photometry and checked by the method of direct comparison. Simple reaction time, the time interval starting with the presentation of a visual stimulus and terminating in a manual response, was used as the method of determining the latencies for the establishment of equal sensory effects for the different wavelengths. Monocular viewing of the stimuli was used by two subjects and reaction times are determined over a luminance range of 5.2 $\log$ units around a central value of 1 millilambert. The results indicated that simple reaction time is inversely related to stimulus luminance. There were no differences in the reaction times to the different wavelengths at the four highest luminance levels; at the lowest luminance level, the wavelengths fan out in a manner that is in line with the classical data of vision. In other words, the visual functions obtained with simple reaction time parallel certain well-known visual functions in intensity discrimination, flicker and visual acuity-the results may be accounted for by the Duplicity Theory of vision.

The problem as to whether or not there are differences in the reaction times to different wavelengths at constant luminance is a question of considerable theoretical and practical significance. The question relates to a large literature in color theory concerning the various visual functions obtained not only with latency measurements but also with critical flicker frequency, intensity discrimination, and visual acuity experiments as well.

In 1906, Henmon, a student of Cattell, measured the time to perceive differences between pairs of colors by the method of disjunctive reaction. Colored cards were used as stimuli and no attempt was made to equate them for luminance. Henmon found that discrimination time was about the same for red and green as for blue and yellow. However, the reaction times for the red-blue and greenyellow combinations were longer for both subjects. In discussing his results, Henmon attributed the differences in perception time for the red and blue to a difference in brightness between the colored stimulus cards while the longer discrimination time for the green and yellow stimuli was ascribed to the proximity of the two colors in the spectrum. In spite of the discrepancies in his data, Henmon maintained that different wavelengths which have been equated for brightness would show no difference in average reaction time.

Another attempt to measure the reaction times to lights of various wavelengths was made by Holmes in 1923. Holmes equated the luminances of the colored lights at one level of luminance with a standard flicker photometer and his results, obtained with two subjects, justlfied his conclusion that simple reaction time is not influenced by the wavelength of the stimulus.

In the same year as Holmes' experiment, Piéron (1923), in order to explain the colorations of the rings produced by rotation of Benham's top, proposed that there was a difference among the timeconstants for sensation of the three fundamental colors of the trichromatic system (Broca-Sulzer effect). The perception of the blue system was the slowest to appear and to reach its transitory maximum, the slowest also to disappear; the red was quickest of the three, and green was interposed between red and blue.

In his theory, Pléron (1952) proposed the independence of the system mediating chromatic and the system mediating brightness sensation. In 1932, Piéron used simple reaction time to study the onset of a chromatic sensation (i.e., reaction time to the perception of color) and found an average minimum latency for red light and an average maximum latency for blue light with a difference of about $30 \mathrm{msec}$ between them. The average reaction time to color for green light was found to be intermediate between the red and the blue. The influence of light of different wavelengths on the latency of the sensation of brightness was determined by Liang and Piéron (1947). They equated their different colored lights for luminance by the method of flicker photometry and checked these luminance matches by direct comparison. They then used the chronostereoscopic (Pulfrich) effect as a measure of latency and found a mean difference in latency of the order of $3.5 \mathrm{msec}$ between red and blue light at a luminance level of .4 nit with red having minimum latency. Individual differences among the three observers used in their study were of the order of magnitude of the latency effect, ranging from 1.5 to $5 \mathrm{msec}$. Although Liang and Pléron, on the one hand, concluded that they could ascertain with assurance that the red light for a given level of luminance had a shorter latency, they also indicated that they had difficulty in ascertaining with 


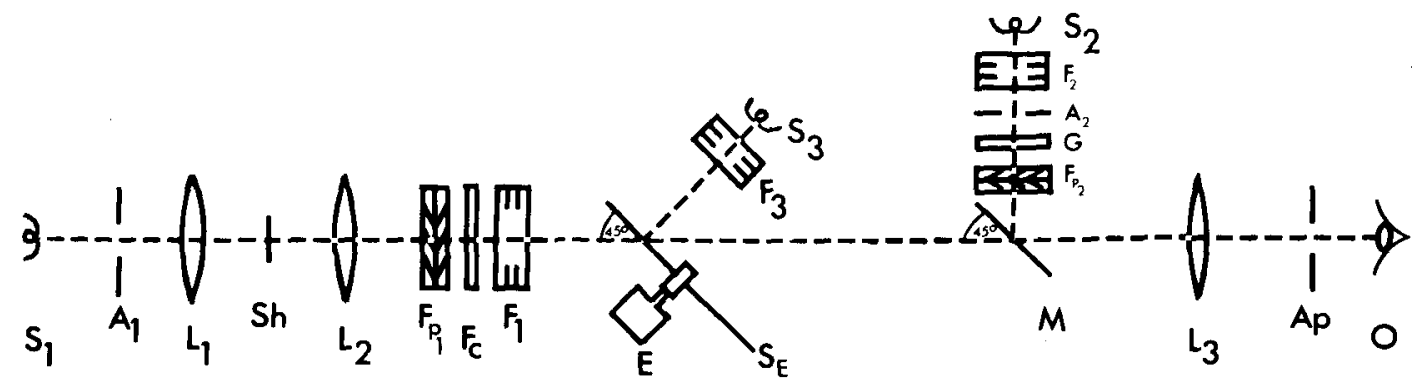

Fig. 1. Schematic presentation of the optical system as described in the text.

complete assurance the equality of luminances of the heterochromatic lights. This latter problem, they said, would therefore make it difficult to formulate a precise quantitative statement of the specific action of the chromatic stimulations. They concluded that the problem that remains posed is that of a possible difference in the law of variation in the reducible margin of the latencies for the different monochromatic luminous excitations of the foveal cones. 3

Liang and Piéron's (1947) results also led to the suggestion that in addition to the possible differences in the speed of perception of light of different wavelengths at the same level of luminance, there was also a possible difference in the law of variation in the reducible margin of the latencies of these different monochromatic lights at different luminances. They felt that the latter law of variation was a point which demanded further research. The present experiment is concerned with determining this law of variation. Simple reaction time is the dependent variable, following Piéron (1932) who used this method to study the speed of establishment of a chromatic sensation for different colored lights.

\section{Subjects}

\section{METHOD}

Two female students with normal color vision as determined by the Ishihara test, Hecht-Shlaer anomaloscope, and Farnsworth Dichotomous test (Panel D-15) were used as experimental Ss. The Ss used monocular vision with the right eye for all measurements. Before the experiment began, both Ss had about $30 \mathrm{~h}$ of experience with flicker photometry and direct comparison matches; while one S (VL) had about $40 \mathrm{~h}$ of practice with reaction times to visual stimuli, the other (EP) had about $10 \mathrm{~h}$ of practice.

\section{Apparatus}

Optical system. Figure 1 shows the optical system of the apparatus. It provided a Maxwellian view of the $2.1^{\circ}$ visual stimulus which was centered in a $10.5^{\circ}$ surround of diffuse light. Source, $S_{1}$, was a GE 1493 filament lamp (color temperature $2854^{\circ} \mathrm{K}$, i.e., Illuminant $A$, as measured by a calibrated optical pyrometer) operated by a $6 \mathrm{~V}$ battery. After passing through aperture $A_{1}$, light from $S_{1}$ was converged to form a reduced image of the filament at the shutter $\mathrm{Sh}$ by condenser lens $\mathrm{L}_{1}$. The light was then collimated by lens $L_{2}$, and focused in the center of the pupil of the observer's eye $O$ by lens $\mathrm{L}_{3}$. The visual stimulus thus presented to the eye at the $3 \mathrm{~mm}$ artificial pupil Ap was approximately $2.1^{\circ}$ of visual angle. The wavelength of the light transmitted by the visual stimulus was varied by appropriate interference filters at $\mathrm{F}_{\mathrm{C}}$; luminous intensity was controlled by means of neutral filters at $F_{1}$, and a pair of polaroids $\mathrm{Fp}_{1}$.

The surround of $10.5^{\circ}$ was furnished by a highly polished stainless steel mirror, M. The mirror had been constructed with an elliptical central opening so that when placed at an angle of $45^{\circ}$ to the midline of the optical bench, the visual stimulus (the central opening) appeared as a circle $2.1^{\circ}$ in diameter. Light from another tungsten source, $\mathrm{S}_{2}$ (color temperature $2854^{\circ} \mathrm{K}$ ), passed through the neutral filters at $F_{2}$, the aperture $A_{2}$, the ground glass $G$, and the pair of polaroids $\mathrm{Fp}_{2}$, and finally filled the mirror M. The ground glass $G$ served to diffuse the light from $\mathrm{S}_{2}$. Luminous intensity of the surround was regulated by means of the neutral density filters used at $\mathrm{F}_{2}$ and by a pair of polaroids $\mathrm{Fp}_{2}$. Fixation was directed to the center of the visual stimulus and head position was maintained by a dental impression bite. A darkroom served to shield the $\mathrm{S}$ from all extraneous light.

The part of the system used for heterochromatic matches involved a sectored aluminum disc $S_{E}$ painted white and a tungsten source $S_{3}$ (color temperature $2854^{\circ} \mathrm{K}$ ). The light from $\mathrm{S}_{3}$ passed through the neutral filter box $F_{3}$ and was then projected on the white surface of the sector of the disc. This disc contained two $90^{\circ}$ sectors $\mathrm{S}_{\mathrm{E}}$ separated by $90^{\circ}$ opaque areas, and was rotated by a dc motor, $E$, at an angle of $45^{\circ}$ to the midline of the optical bench. The Bodine Electric Co. dc motor, Type NSH-34, of the disc was controlled by a General Radio Co. variac speed control, Type No. 1701-AK.

The method of flicker photometry was used to 
determine equal luminances of the six different light stimuli, each of which was flickered with a standard white light which had a value of $1.3 \log \mathrm{mL}$. The eye placed behind the artificial pupil Ap observed in the $2.1^{\circ}$ field the colored test light from source $S_{1}$ flickered against the disc illuminated by $S_{3}$. This $2.1^{\circ}$ field was situated in the center of the $10.5^{\circ}$ white surround illuminated by $S_{2}$. The disc and the surround were maintained at a constant luminance of $1.3 \mathrm{log} \mathrm{mL}$. The luminance of the colored lights was adjusted by neutral filters at $F_{1}$ and a pair of polaroids $\mathrm{Fp}_{1}$. The standard luminance of 1.3 $\log \mathrm{mL}$ was measured with an SEI (Ilford) Exposure photometer. When readings were taken at the position of the observer's eye, $O$, the results with and without lens $\mathrm{L}_{3}$ were identical, 1.e., $1.3 \log \mathrm{mL}$. The surround was matched by the observers by the method of direct comparison to the luminance of the visual stimulus when the latter was illuminated by: (1) the white disc of the flicker photometer at $1.3 \log \mathrm{mL}$, and (2) the colored test lights which had equal luminances as determined by flicker photometry at $1.3 \log \mathrm{mL}$. The average matching value of the surround to the visual stimulus was the same for both Ss under both conditions. Neutral filters, calibrated with a Martens Polarization photometer for white light and every colored light used in the experiment, regulated intensities above and below the standard level (1.3 log $\mathrm{mL}$ ) for both the surround and the colored visual field. It is interesting to note that the results obtained by flicker photometry for the different colored test lights at $1.3 \log \mathrm{mL}$ were checked against those obtained by this method at $0.9 \log \mathrm{mL}$ and agreement to within $\pm 0.08 \mathrm{log} \mathrm{mL}$ was found.

The color of the visual stimulus was varied by using six interference filters of dominant wavelength $415,462,505,530,589$, and $657 \mathrm{~m} \mu$ as calibrated on the Beckman Spectrophotometer, Model DU. Transmission curves of the three Schott interference filters $(462,530$, and $657 \mathrm{~m} \mu)$ were relatively narrow $(12,13,12 \mathrm{~m} \mu$, respectively, at half maximum transmission) while transmission curves of the three Farrand interference filters $(415,505,589 \mathrm{~m} \mu)$ were wider $(17,30,16 \mathrm{~m} \mu$, respectively, at half maximum transmission) and not as symmetrical as the Schott filters.

Reaction Time Apparatus. Closing the S's reaction time key triggered the programming equipment which started the motor of a variable interval (VI) timer. When this timer reached the programmed hole on a punched tape, the motor of the VI timer stopped; then simultaneously the shutter (Sh) of the optical system (Fig. 1) opened, and by means of a linked mercury relay, the millisecond counter was activated. Opening the S's reaction time key simultaneously closed the shutter and stopped the millisecond counter. ${ }^{4}$ The millisecond counter was a simple electronic digital counter, utilizing Hewlett-Packard $A C-4 \mathrm{~A}$ decade units. The timing signal driving the decade units was a 1000 cps tone produced by a Hewlett-Packard $200 \mathrm{AB}$ audio oscillator. The audio oscillator was calibrated before and after each experimental session by the Lissajous pattern produced when its frequency was compared with a General Radio $1000 \mathrm{cps}$ vacuum-tube fork, Type No. 723-C. Calibration after each experimental session revealed that the audio oscillator had a drift at 1000 cps of not more than +.333 cps and not less than $+.167 \mathrm{cps}$; and the accuracy rating of the vacuum-tube fork was \pm .10 cps when checked against a Hewlett-Packard frequency standard; therefore, the measured error of the reaction time scores was within +.067 to $+.443 \mathrm{msec}$.

\section{Procedure}

After $10 \mathrm{~min}$ of dark adaptation, the $\mathrm{S}$ looked through a viewing tube and saw the circular visual stimulus of $2.1^{\circ}$ which was located in the center of the $10.5^{\circ}$ white circular surround. Three minute light adaptation was then produced by the $10.5^{\circ}$ circular background, i.e., before the presentation of the colored test lights to the $\mathrm{S}$, she was adapted for 3 min to a field which was of the same luminance as the visual stimulus which was to be presented. The $S$ was requested to maintain central fixation throughout the experimental session, and upon receiving a "ready" signal from the $E$, the $S$ fixated the center of the dark visual stimulus and held down the reaction time key. By pressing down the RT key, the $S$ closed a circuit to the VI timer which introduced a variable foreperiod (mean delay: $2 \mathrm{sec}$ ) before the presentation of each spectral light to the eye. When the $S$ saw the colored light, she released her RT key. The $\mathrm{E}$ then recorded the reading from the millisecond counter. A trial was terminated after $740 \mathrm{msec}$ by the $E$ if the $S$ did not respond. There were at least 25 sec between trials; and after Trial No. 60 and Trial 120, a $45 \mathrm{sec}$ rest period was given. Eighteen "catch" trials were interspersed randomly among the experimental trials.

Reaction times to different colored lights were determined at five luminance levels $(-2.6,-1.3,0.0$, 1.3 , and $2.6 \log \mathrm{mL}$ ). The order of luminance levels was varied randomly for different experimental days, while the order of wavelengths was varied randomly within an experimental session. Thus, for each experimental session, luminance was held constant. For four luminance levels, six wavelengths $(415,462,505,530,589$, and $657 \mathrm{~m} \mu)$ were varied randomly over the 180 total trials of the session (six wavelengths, 30 trials per wavelength), while at the highest luminance level of $2.6 \log \mathrm{mL}$, four wavelengths $(505,530,589$, and $657 \mathrm{m \mu})$ were varied randomly over the 180 trials of the session (four wavelengths, 45 trials per wavelength). Ten practice 
trials were given before the 180 trials of each experimental session. Each of the five luminance levels was presented in random order (on different days) until the $E$ 's criterion of stable reaction time data was reached on three experimental days. Thus, there were at least 15 experimental days for each $S$ (five luminance levels, three experimental days per luminance level).

The criterion of reaction time stability used in this experiment was adopted in order to insure reliability of the data at each level of luminance. The data from each experimental session were divided into three parts and the medians of each third of the data were recorded, i.e., the median of Trials 1-60, of Trials $61-120$, and of Trials 121-180. However, only the medians from Trials $61-120$ and of Trials 121-180 were examined for stability, and the data were considered acceptable when the highest and lowest of the medians obtained from three experimental days did not differ by more than $15 \mathrm{msec}$. The $E$ decided to adopt the above criterion because pilot work at $0.0 \log \mathrm{mL}$ with both Ss showed that the median of the first 60 trials was lower by approximately $20 \mathrm{msec}$ than the medians of Trials 61-120 and Trials $121-180$ in about $80 \%$ of the experimental sessions. Therefore, the $E$ thought that the data from the first third of the session might have to be analyzed separately. However, in the main experiment adding the data from the first third of the sessions to that from the latter two-thirds of the sessions did not appear to change the general form of the functions obtained.

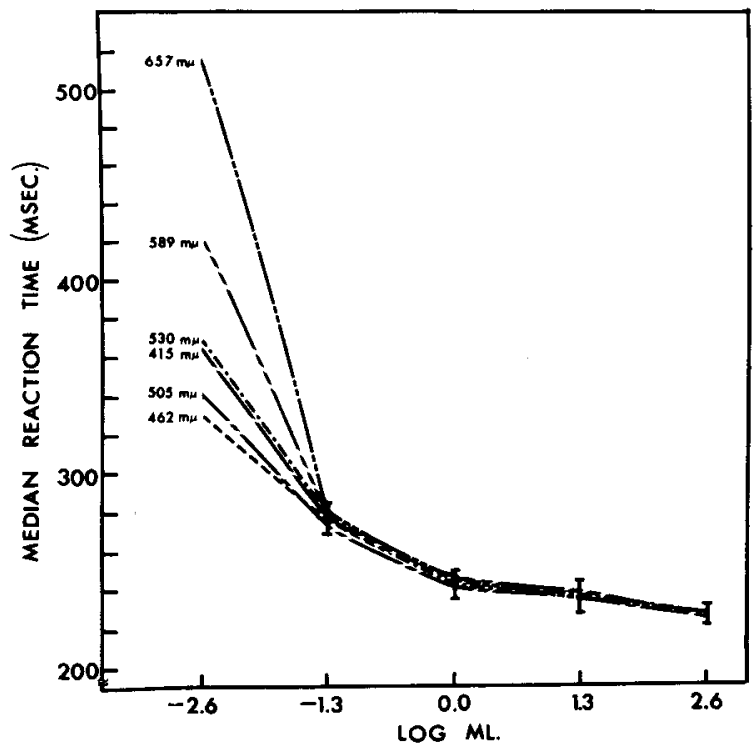

Fig. 2. Median reaction times (msec) for Subject EP determined as a function of wavelength at five levels of luminance. The variability of these frequency distributions of reaction times is shown in terms of the .01 confidence interval of each median, except at the lowest Iuminance level of $-2.6 \log \mathrm{mL}$.

\section{RESULTS}

Median reaction times (msec) for subject EP determined as a function of wavelength at each level of luminance studied are presented in Fig. 2. The variability of these frequency distributions of reaction times is established in terms of the .01 confidence interval of each median at the four highest intensity levels where the confidence bounds of each wavelength overlap. At the lowest intensity level of $-2.6 \log \mathrm{mL}$, the confidence bounds do not overlap; therefore they are not shown in this figure. The confidence intervals were determined by the method of Nair (1940).

From Fig. 2 it appears that reaction time is inversely related to stimulus luminance and that there are no appreciable differences in the reaction times to the different wavelengths at luminance levels of $-1.3,0.0,1.3$, and $2.6 \mathrm{log} \mathrm{mL}$. (Multiply each luminance value in $\mathrm{mL}$ by 22.5 to obtain the corresponding retinal illuminance values in trolands uncorrected for the Stiles-Crawford (1933) effect.) Moreover, Fig. 2 shows that, in general, as the spectrum changes from blue to red, the median reaction time for each wavelength increases, while the median reaction time for a violet of $415 \mathrm{m \mu}$ falls between that for a blue-green of $505 \mathrm{~m} \mu$ and that for a yellow-green of $530 \mathrm{~m} \mu$.

Under comparable luminance conditions, the reaction times of the other $\mathrm{S}, \mathrm{VL}$, are consistently higher than those of Subject EP and the variability is also proportionately greater. However, the data of both Ss present essentially the same picture, consequently, only the data for Subject EP are presented.

Figure 3 presents the pooled cumulative frequency distributions for all the wavelength distributions used at luminance levels of $-1.3,0.0,1.3$, and 2.6 $\log \mathrm{mL}$ for Subject EP. Each of these four pooled frequency distributions consists of 540 reaction times. It should be noted that at the highest luminance level of $2.6 \log \mathrm{mL}$, the pooled cumulative frequency distribution is the result of combining four wavelengths (135 reaction times per wavelength) while the remaining three pooled distributions are the result of combining six wavelengths (90 reaction times per wavelength). The justification for combining the wavelengths at these four luminance levels is based on the assumption that the frequency distribution for the different wavelengths used at each level of luminance (except at the lowest luminance of $-2.6 \log \mathrm{mL}$ ) are taken from the same (or nearly the same) distribution. This assumption is not entirely arbitrary since the .01 confidence intervals for the medians overlap at these luminance levels. The distributions illustrated are quite similar to related data on simple reaction time observed in another sensory area (Greenbaum, 1963). 


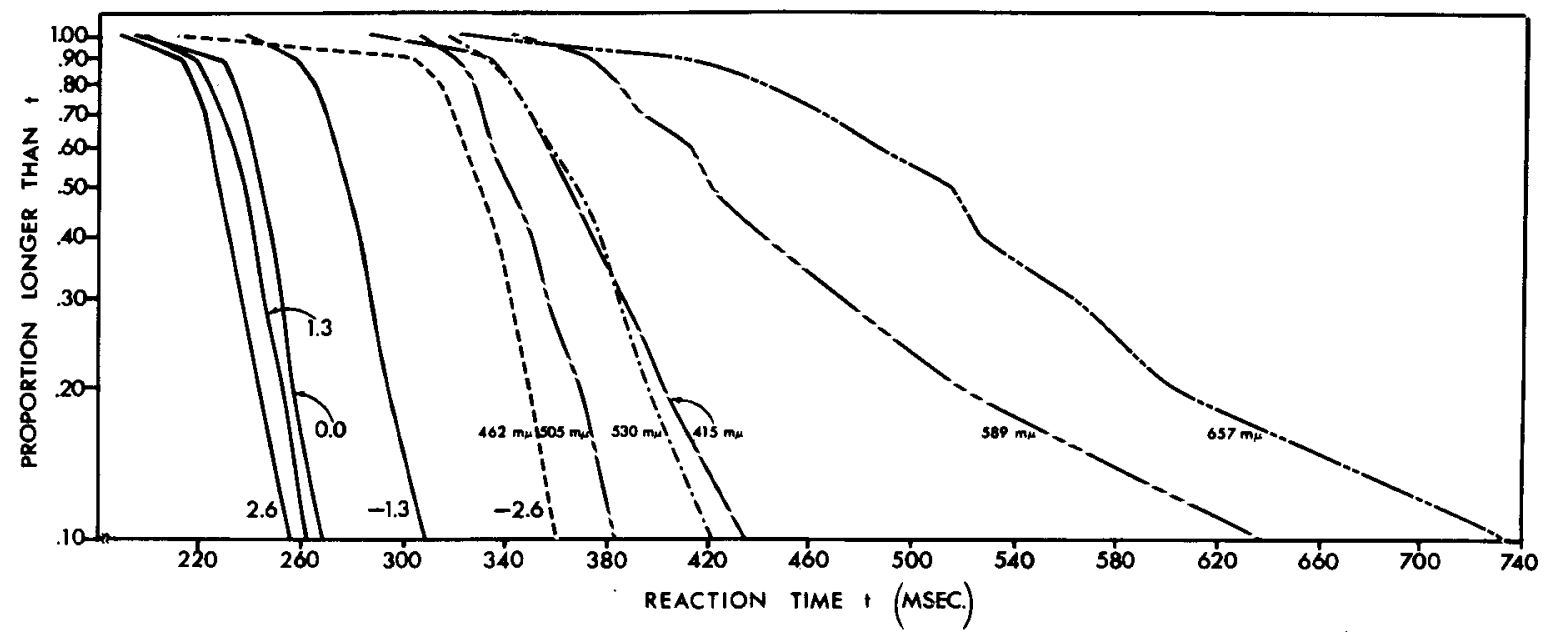

Fig. 3. The pooled cumulative frequency distributions for all wavelengths used at luminance levels of $-1.3,0.0$, 1.3 and $z: 6 \log \mathrm{mL}$ for Subject EP. Each of these pooled frequency distributions consists of 540 reaction times. At the lowest luminance level of $-2.6 \log \mathrm{mL}$, the cumulative frequency distribution for each wavelength is presented for this same subject. Each of these frequency distributions consists of $\mathbf{9 0}$ reaction times.

The cumulative frequency distributions of reaction times for each wavelength $(\mathrm{N}=90$ reaction times per wavelength) at the lowest luminance level of $-2.6 \log \mathrm{mL}$ for Subject EP are also shown in Fig. 3 . It is apparent from this figure that at the lowest luminance, as the spectrum changes from blue to red, the frequency distribution of reaction times for each wavelength is displaced to the right, i.e., for the same percentile or proportion, the reaction times, in general, become longer as wavelength increases. The cumulative frequency distribution for violet $(415 \mathrm{~m} \mu)$ appears near the frequency distribution for yellow-green $(530 \mathrm{~m} \mu)$.

At the lowest luminance level, there is a marked difference in reaction time associated with wavelength. The effect is illustrated in Figs. 2 and 3 and is also to be seen in Fig. 4, which shows a family of constant reaction time curves for Subject EP. These differences are not seen at the higher levels of luminance in our data.

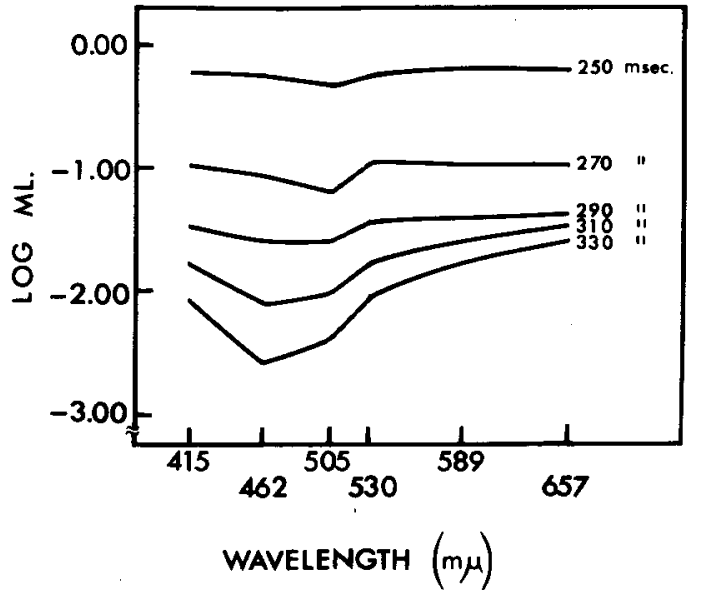

Fig. 4. Constant reaction time curves for Subject EP
The data for Fig. 4 are derived from Fig. 2 and are presented in Table 1 . Curves of constant reaction time were produced by choosing a time on the graph of Fig. 2 and then reading the log luminance level in $\mathrm{mL}$ for each wavelength at this value of the reaction time. With the assumption that equal reaction times indicate equal sensory effects (as was demonstrated in Figs. 2 and 3 for the four highest luminance levels), it is seen in Fig. 4 that at low luminance levels, the contour resembles the scotopic luminosity function for a low luminance level sensory effect; but the higher the level of sensory effect, the more the contour flattens out. The curves are derived in the manner suggested by Chocholle (1940-1941, 1944-1945) who obtained constant reaction time contours at various sound intensities for different frequencies. In the present study, the contours were obtained across different wavelengths. The wavelength effect on reaction time noted earlier is seen in Fig. 4 as the dip in the blue and blue-green regions of the spectrum.

\section{DISCUSSION}

The results show that reaction time is inversely related to stimulus luminance, and the appreciable differences in the reaction times to the different wavelength distributions are found only at the lowest luminance level. This effect at the lowest luminance is in line with classical data as will be shown.

The finding that there is no appreciable difference in reaction time to the different wavelength distributions at the four highest luminance levels agrees with the conclusions of Henmon (1906) and Holmes (1923). However, it does not support Liang and Piéron's (1947) belief that a red light for a given level of luminance had a smaller latency than a blue light. These authors could not claim equality of luminance among the heterochromatic lights used 
Table 1. Luminance in $\log \mathrm{mL}$ for each wavelength at a constant median reaction time for subject EP. These data are derived from Fig. 2. This table also shows the relative luminous efficiency of radiation $\left(V_{\lambda}\right)$ and log $v_{\lambda}$ for each wavelength. The values of $V_{\lambda}$ presented have been obtained from a table in Walsh (1958) which was constructed by interpolation between the internationally adopted values of $v_{\lambda}$. The estimated logs of radiance (or radiant energy flux) shown have been obtained by subtracting $\log \mathrm{V}_{\lambda}$ from luminance (or luminance flux or $\mathrm{F}$ ) in $\log \mathrm{mL}$.

\begin{tabular}{|c|c|c|c|c|c|c|c|}
\hline Photometric quantity & Constant Reaction & & & Wavel & & & \\
\hline $\begin{array}{l}\text { Luminance or } \\
\text { luminous flux } \\
\text { or } F \\
(\log \mathrm{mL})\end{array}$ & $\begin{array}{l}250 \\
270 \\
290 \\
310 \\
330\end{array}$ & $\begin{array}{l}-0.25 \\
-0.98 \\
-1.48 \\
-1.77 \\
-2.08\end{array}$ & $\begin{array}{l}-0.25 \\
-1.05 \\
-1.60 \\
-2.10 \\
-2.59\end{array}$ & $\begin{array}{l}-0.35 \\
-1.20 \\
-1.60 \\
-2.03 \\
-2.40\end{array}$ & $\begin{array}{l}-0.25 \\
-0.95 \\
-1.43 \\
-1.74 \\
-2.03\end{array}$ & $\begin{array}{l}-0.21 \\
-0.98 \\
-1.40 \\
-1.59 \\
-1.77\end{array}$ & $\begin{array}{l}-0.22 \\
-0.98 \\
-1.37 \\
-1.47 \\
-1.58\end{array}$ \\
\hline $\begin{array}{l}\text { Estimated } \\
\text { Log rodiance } \\
\text { or } \\
\text { Log radiant } \\
\text { energy flux }\end{array}$ & $\begin{array}{l}250 \\
270 \\
290 \\
310 \\
330\end{array}$ & $\begin{array}{l}2.4076 \\
1.6776 \\
1.1776 \\
0.8876 \\
0.5776\end{array}$ & $\begin{array}{r}0.9371 \\
0.1371 \\
-0.4129 \\
-0.9129 \\
-1.4029\end{array}$ & $\begin{array}{r}0.0404 \\
-0.8096 \\
-1.2096 \\
-1.6396 \\
-2.0096\end{array}$ & $\begin{array}{l}-0.1855 \\
-0.8855 \\
-1.3655 \\
-1.6755 \\
-1.9655\end{array}$ & $\begin{array}{l}-0.0959 \\
-0.8659 \\
-1.2859 \\
-1.4759 \\
-1.6559\end{array}$ & $\begin{array}{r}0.9167 \\
0.1567 \\
-0.2333 \\
-0.3333 \\
-0.4433\end{array}$ \\
\hline
\end{tabular}

in their study since their results obtained with flicker photometry and direct comparison did not uniformly agree. They found good agreement between these two phtotmetric methods for green light, a small difference for red light, and great disagreement between the methods for blue light.

If there are differences in the reaction times to the different colored lights at the higher luminance levels used in this study, they are not large. Liang and Pieron's (1947) study suggests that these differences would be of the order of 3 to $4 \mathrm{msec}$. In order for the differences between wavelengths to be considered significant, in terms of the .01 confidence interval of the medians obtained in this experiment, the differences would have to be of the order of at least 10 to $20 \mathrm{msec}$ for the number of determinations made. To find significant latency differences of about 3 to $4 \mathrm{msec}$ among the different wavelengths, using our reaction time method, an unusually large number of trials would have to be obtained.

The functions obtained in the present study with visual reaction times (see Figs. 2 and 3 ) parallel certain well known visual functions bearing on the Duplicity Theory: Discriminations at high intensities are determined by cones; at low intensities, they represent the function of rods. It is probable that, at mesopic intensities, mixtures of rods and cones are involved (Hecht, 1937).

Why do the curves for the different wavelengths line up as they do in our experiment and in the classical data of intensity discrimination (Hecht, Peskin, \& Patt, 1938) and CFF (Hecht \& Shlaer, 1936)? In all these figures, the data break into two sections. The high luminance portion which Hecht, Peskin, and Patt (1938) and Hecht and Shlaer (1936) identified with cone function, fall together for all the colors. At low luminances, the functions consist of branches which may be identified with rod func- tion. When one examines the functions of Figs. 2 and 3 at low luminances, one sees that, in general, the curves appear in spectral order going from blue to red with that for violet falling near the curve for yellow-green. Hecht, Peskin, and Patt (1938) and Hecht and Shlaer (1936) maintain that the separation of rod and cone sections as a whole increases as wavelength decreases.

A better understanding of the effect taking place is gained from Fig. 5, which shows estimated log radiance as a function of wavelength for five constant reaction times. Since equal reaction times may be taken to indicate equal sensory effects (as was demonstrated in Figs. 2 and 3 for the four highest luminance levels), a constant reaction time was chosen on the graph of Fig. 2 for Subject EP and

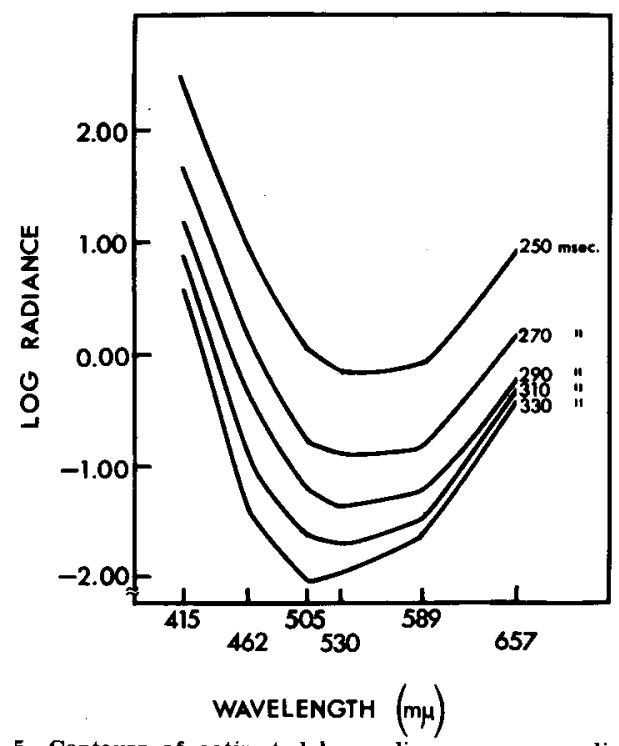

Fig. 5. Contours of estimated $\log$ radiance corresponding to a constant reaction time for each of the wavelengths used in this experiment. The estimations were made from the data of Subject EP by the method described in Table 1 and in the text. 
then the luminance level in $\log \mathrm{mL}$ was read for each wavelength at that value of constant reaction time as is shown in Table 1. This table also shows how the estimated log radiances were determined. Thus Fig. 5 shows contours of estimated log radiance corresponding to a constant reaction time for each of the wavelengths used in the present experiment. This figure provides a series of estimated energy functions. From Fig. 5 it is seen that as reaction time increases, the wavelength of maximum luminous efficiency decreases. This effect is known as the Purkinje shift and is caused by the transfer from rod to cone vision or by the admixture of rod and cone vision. The data of Hecht and Shlaer (1936) and Hecht, Peskin, and Patt (1938) could also provide a series of estimated energy curves that represent the transfer from rod to cone vision or an admixture of rods and cones at the lowest luminance levels.

In line with this description, it is proposed that the present results for the lowest luminance level of $-2.6 \log \mathrm{mL}$ are due to an admixture of rods and cones. If one examines Fig. 5 , it is seen that the estimated energy function for the fastest reaction time of $250 \mathrm{msec}$ (which is Subject EP's approximate median reaction time for each of the wavelength distributions at a luminance level of $0.0 \log \mathrm{mL}$, see Fig. 2) resembles the photopic energy function associated with the spectral sensitivity curve for the cones (see Hecht \& Hsia, 1945). The estimated energy function is also shown in Fig. 5 for the slowest reaction time of $330 \mathrm{msec}$. (This is Subject EP's approximate median reaction time to blue at the lowest luminance level of $-2.6 \mathrm{log} \mathrm{mL}$. It should also be noted that at this luminance level, Subject EP gave a faster reaction time to blue than to any other wavelength distribution.) The curve for this estimated energy level resembles the scotopic energy function which has been associated with the spectral sensitivity curve for the rods (Hecht \& Hsia, 1945). Therefore, rods may be said to be playing a dominant part in the reaction times obtained at the lowest luminance level. However, cones are also playing a role. At this lowest luminance level, the Ss reported seeing color. Thus, the functions at the lowest luminance level, represented by the branches of the reaction time curves (see Fig. 2), probably represent the activity of both rods and cones.

Brooke (1951) and Lloyd (1952) interpreted some of their results with CFF by stating that rods function and interact with cones at levels of luminance that are often considered to be photopic. The present results with reaction time seem to point to the fact that cones function and interact with rods for some wavelength distributions at a level of luminance which is often considered to be scotopic (-2.6 log $\mathrm{mL}$ ). The Duplicity Theory states that the vertebrate retina contains two different kinds of receptors -cones and rods (Hecht, 1937). The present interpretation of data cannot be certain of the luminance level where rod function stops and cone function begins; the mesopic region is a treacherous but fascinating area. In any case, the visual functions obtained with flicker, intensity discrimination, and visual acuity (Hecht, 1937) and simple reaction time all strikingly fall into the pattern presented by the Duplicity Theory.

Consequently, since the visual functions obtained in this experiment by the use of simple reaction time parallel various well established visual functions, the validity of simple reaction time as a psychophysical method is given fresh impetus. In the past, there have been indications of agreement between the results of the reaction time method and established psychophysical data, as the experiments in intensity discrimination using reaction time to change as a method have shown (for example, the experiments of Steinman (1944) and Hecht (1934, p. 761)). In her experiments with human Ss, Steinman found that the stimulus-ratio required for a liminal brightness increment decreased as a function of intensity in the manner of the classical data of König and Brodhun (Hecht, 1934), which did not use simple reaction time as a dependent variable.

Hecht (1934) made measurements of the time required by the clam, Mya, for its characteristic response to light (i.e., simple reaction time to change) and found that in spite of the difference in complexity between the two visual systems, human intensity discrimination (the König and Brodhun data; see Hecht (1934)) functions in a manner similar to that described for Mya. The results obtained using simple reaction time and simple reaction time to change are therefore consistent with those obtained by other psychophysical methods. Our data seem to offer useful applications of reaction time methods for investigating color effects and differences between rod-cone functions. Moreover, with luminances in the photopic regions, simple reaction time (with a stable S) seems to provide a rough but simple way to accomplish heterochromatic luminance matching.

\section{References}

Brooke, R. T. The variation of critical fusion frequency with brightness at various retinal locations. J. Opt. Soc. Amer., 1951, $41,1010-1016$.

Chocholle, $\mathbf{R}$. Variation des temps de réaction auditifs en fonction de l'intensité à diverses fréquences. Année psychol., 1940-41, 41-42, 65-124.

Chocholle, R. Etude de la psychophysiologie de l'audition par la methode des temps de réaction. Annće psychol., 1940-45, 45$46,90-131$.

Greenbaum, H. B. Simple reaction time: A case study in signal detection. Thesis (Ph.D.), Columbia University, 1963. Microfilm or Xerox copy available from University Microfilms, Inc: Ann Arbor, Michigan. Order No. 63-7421 
Hecht, S. Vision: II. The nature of the photoreceptor process. In C. Murchison (Ed.), Handbook of general experimental psycholo$g y$. Worcester: Clark University Press, 1934.

Hecht, S. Rods, cones, and the chemical basis of vision. Physiol. Rev., 1937, 17, 239-290.

Hecht, S., \& Hsia, $\boldsymbol{x}$. Dark adaptation following light adaptation to red and white lights. J. Opt. Soc. Amer., 1945, 35, 261-262

Hecht, S., Peskin, J. C., \& Patt, M. Intensity discrimination in the human eye. Il. The relation between $\Delta \mathrm{I} / \mathrm{I}$ and intensity for different parts of the spectrum. J. gen. Physiol., 1938, 22, 7-19.

Hecht, S., \& Shlaer, S. Intermittent stimulation by light. V. The relation between intensity and critical frequency for different parts of the spectrum. $J$. gen. Physiol., 1936, 19, 956-977.

Henmon, V. A. C. The time of perception as a measure of differences in sensations. Arch. Philos., Psychol., \& Sci. Me th., 1906 No. 8, 36-38.

Holmes, J. L. Reaction time to light as conditioned by wavelength and intensity. Unpublished thesis (Ph.D.), Columbia University 1923.

Liang, T., \& Piéron, H. Recherches sur la latence de la sensation lumineuse par la méthode de l'effet chronostéréoscopique. Année psychol., 1947, 43-4, 1-53.

Lloyd, V. V. A comparison of critical fusion frequencies for different areas in the fovea and periphery. Amer. J. Psychol., 1952 65, 346-357.

Nair, K. R. Table of confidence interval for the median in samples from any continuous population. Sankhy $\bar{a}, 1940,4,551-558$.

Piéron, H. Le mécanisme d'apparation des couleurs subjectives de Fechner-Benham. Année psychol., 1923, 23, 1-49.

Piéron, H. La sensation chromatique. Données sur la latence propre et l'etablissement des sensations de couleur. Année psychol, $1932,32,1-29$.

Piéron, H. The sensations: their functions, processes and mechanisms. Translated by M. H. Pirenne and B. C. Abbott. New Haven Yale University Press, 1952.
Steinman, A. R. Reaction time to change compared with other psychophysical methods. Arch. Psychol., 1944, No. 292.

Stiles, W, S., \& Crawford, B. H. Luminous efficiency of rays entering the eye pupil at different points. Proc. Roy. Soc., 1933, 112B, 428-450

Walsh, J. W. T. Photometry. (3rd ed.) London: Constable and Company, Ltd, 1958.

Woodworth, R. S., \& Schlosberg, H. Experimental psychology. (Rev. ed.) New York: Henry Holt and Company, 1954

\section{Notes}

1. This document is Technical Report No. 38, of Contract No. 266(46), between Columbia University and the Office of Naval Research. The work is part of the program of Project No. 142-404 Reproduction in whole or in part is permitted for any purpose of the United States government. Support has also been provided by the Institutional Scientific Research Pool of Columbia University. 2. Present address: Department of Zoology, University of California, Los Angel es.

3. According to Piéron, any reaction time is composed of a limiting value or "irreducible minimum" plus a remainder which he calls a "reducible margin." The reducible margin depends on the experimental variable (intensity, wavelength) while the irreducible minimum depends on the factors that are held constant, such as practice, attitude, and sensory modality used (Woodworth and Schlosberg, 1954).

4. Thus, exposure time for the light was equal to reaction time. Since this time, as shown by the experimental data of Figure 3, was less than $200 \mathrm{msec}$, the duration of light was always at least twice the usual critical duration $(100 \mathrm{msec})$ that limits integration of intensity effects. It is in the range where effect is little affected by increase in time of exposure.

(Accepted for publication September 12, 1967.) 